\title{
Growth and Characterization of Bio-semiorganic (Ficus religiosa Chlorophyll- a) Doped Potassium Dihydrogen orthophosphate (KDP) Crystal
}

\author{
S. Senthilkumar ${ }^{1}$ C. Ramachandra Raja ${ }^{2}$, R. Manimekalai ${ }^{3 *}$ \\ ${ }^{1}$ Department of Physics, Parisutham Institute of Technology and Science, Thanjavur-613006, Tamilnadu, India \\ ${ }^{2}$ Department of Physics, Government arts college (Autonomous), Kumbakonam - 612001, Tamilnadu, India \\ ${ }^{3}$ A.V.V.M. Sri Pushpam College (Autonomous), Poondi- 613 503, Tamilnadu, India \\ *Corresponding Author: maniabi64@gmail.com, Tel.: +919942544718
}

Available online at: www.isroset.org

Received: 20/Apr/2019, Accepted: 26/Apr/2019, Online: 30/Apr/2019

\begin{abstract}
In present investigation, Potassium dihydrogen orthophosphate (KDP) doped with Bio-semiorganic (Ficus religiosa Chlorophyll-a) novel crystal was grown by slow evaporation solution growth method. The presence of different functional groups has been analyzed by FT-IR spectral analysis. The cell parameters of the KDP doped with Ficus religiosa Leaves Chlorophyll-a crystal was determined using single crystal X-ray diffraction analysis. UV-vis-NIR transmission spectra recorded for the grown crystals reveal the optical transparency and optical quality, energy gap, refractive index and reflectance. Using energy dispersive X-ray spectroscopy (EDAX), the presence of the elemental composition with weight percentage has been calculated. The Vicker's microhardness studies of doped crystals have been carried out at different loads. Further, the Vicker's microhardness as well as parameters such as yield strength $\left(\sigma_{V}\right)$, fracture toughness $(\mathrm{Kc})$, brittleness index $(\mathrm{B})$ are presented. The spectral and luminescent properties of Chlorophyll-a Doped Potassium dihydrogen orthophosphate (KDP) Crystal were analyzed.
\end{abstract}

Keywords-FTIR, UV-Vis-Spectra, Hardness, Single crystal-XRD, E-DAX, Photoluminosence.

\section{INTRODUCTION}

KDP crystal has aroused considerable interest among several researchers because of its wide frequency conversion, high efficiency of frequency conversion, good UV transmission, high damaged threshold against high power laser and high birefringence through its NLO coefficients are relatively low [1-3]. It is more fashionable to all. Now - a days, great attention has been devoted to the growth and characterization of pure and doped crystals, with the aim of finding new material for practical purpose. The presence of impurities has various effects in both habit modification and crystal properties [4-7]. The growth of the KDP (Potassium dihydrogen orthophosphate) and Ficus religiosa Leaves Chlorophyll-a(CHLAKDP) by the slow evaporation technique which is one of the simplest techniques have been undertaken in the present work. Peepal tree, scientific name Ficus religiosa belongs to the family of Moraceae. It is also known as ashwattha tree or Bodhi tree (in Nepal and India). Peepal tree is also a chief oxygen provider. The peepal tree is rich in aspartic acid, tannic acid, flavonoids, methionine ,steroids, vitamins, glycine, etc. According to Ayurveda, every part of the peepal tree - the leaf, shoot, bark, seeds, as well as the fruit, has several medicinal benefits. It is being used since ancient times for curing many diseases such as Jaundice, Constipation, Heart Diseases, Diabetes Management, etc... Chlorophyll is a green pigment in leaves and green terms of plant. In the beginning, it was assumed that chlorophyll was a single compound, but in 1864 Stokes discovered by spectroscopy that chlorophyll is not single. If dried leaves are powdered and dissolved in ether or aqueous acetone, amorphous chlorophyll is obtained. If ethanol is used, the product is "crystalline" chlorophyll. It showed that chlorophyll was a mixture of two compounds such as chlorophyll- a and chlorophyll -b. Chlorophyll- a Molecular Formula- $\left(\mathrm{C}_{55} \mathrm{H}_{72} \mathrm{MgN}_{4} \mathrm{O}_{5}\right)$ : Molecular Weight-893.49 Chlorophyll is composed of two parts, a substituted porphyrin ring and phytol (the long carbon chain).The porphyrin ring is an excellent chelating legand with the four nitrogen atoms binding strongly to a coordinate metal atom in a square planar arrangement. Chlorophyll is an excellent source of vitamin- $\mathrm{k}$ and calcification of bone. Chlorophyll can be used to stimulate production of testosterone in a male, estrogen in female and restoring hormones into balance. It is used before surgical operations there will less need for analgesics and relieve the load on the liver [8]. It detoxifies the additional 
drugs and reduce blood pressure. The potential of chlorophyll as a cancer preventative agent [9].

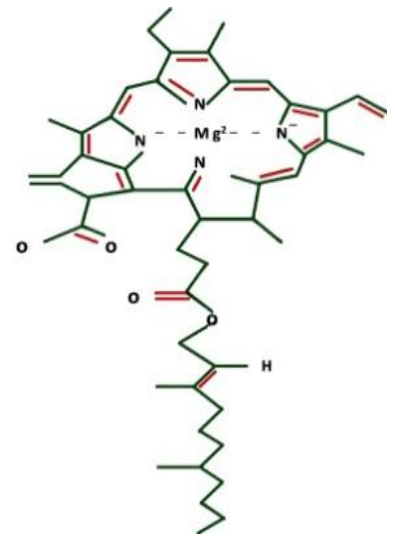

Fig.1 Chlorophyll A

It is considered to be wonderful blood builders and can be used in anticancer and antioxidant properties [10]. Researchers are excited about its potential for cancer therapy. One study revealed that men having lower level of dietary chlorophyll had a higher risk of colon cancer [11]. From this motivation KDP and Chlorophyll-a of Peepal Leaves were used as additive agent to prepare crystal using slow evaporation technique. The grown crystal has been investigated through various techniques, namely Fourier transform infrared spectroscopy (FT-IR), UV-Vis Spectroscopy, Single crystal X-ray Diffraction (single XRD), Energy Dispersive X-ray spectroscopy (EDAX), Vicker's Micro hardness and the photoluminescence analysis (PL).

Section I contains the introduction of the Biosemiorganic KDP Crystal, Section II contains the related work of grown crystal, Section III contains the materials and methods, Section IV contains the result and discussion and section V explain the conclusion and future scopes.

\section{RELATED WORK}

Nowadays, researchers have focused on detecting high quality synthesis materials from the complex crystal. There has been a vast report through the development of novel single crystals using the chemical compounds such as kdp and chlorophyll a. The optical, mechanical and electrical properties of ginger doped kdp single crystals are reported by P.R Deepthi and k. Vijayakumarannair, in the paper titled "growth and characterization of ginger extract doped kdp crystal". Like, mechanical properties of amino acid l-arginine doped with kdp are reported by E.F. Dolzhenkova, E.I. Kostenyukova, O.N. Bezkrovnaya, I.M. Pritula , in the paper titled Effect of doping of KDP crystal with amino acid Larginine on the strength properties and character of laser damage In this present work, the chlorophyll a added with kdp (CHLAKDP) to grow a novel single crystal. The grown crystal is expose to study its optical and mechanical properties and cell parameters, From the studied results, their characteristics are scrutinized in this work.

\section{MATERIALS AND METHODS}

Potassium dihydrogen orthophosphate (KDP) is a well- known inorganic salt. The solution of KDP salt is prepared in saturated conditions. This KDP solution was stirred well for two hours continuously. Clean some Ficus religiosa leaves with water and dry it with a paper towel. Cut $2 \mathrm{~g}$ of Ficus religiosa leaves into small pieces with scissors and put into the mortar. Add $3 \mathrm{ml}$ of acetone into a mortar and crush the leaves with the pestle. Transfer the solution through a filter funnel with a piece of cotton wool to a screwcap test tube and squeeze the residue for getting more extract Pour $3 \mathrm{ml}$ of acetone into the mortar and crush the residue with the pestle again. Pour the liquid into the test tube through the filter funnel. Then pour $5 \mathrm{ml}$ of hexane and $3 \mathrm{ml}$ of acetone into the mortar and crush the residue again and then filter the extract into the screw-cap test tube. The residue left over very pale green. Pour $3 \mathrm{ml}$ of brine into the screwcap test tube. Put on the cap tightly and shake the screw-cap test tube powerfully to wash the chlorophyll-acetone-hexane solution. Open the screw cap of the test tube periodically to release the gas pressure. Then set the tube back in the testtube rack and permit the mixture to separate. The top layer was a dark green and the bottom layer clear. If mixture is hard to separate, add some brine to facilitate the separation. By using a dropper, segregate and collect the organic layer to a clean screw-cap test tube (or to discard the bottom aqueous layer). Add enough anhydrous sodium sulphate to the solution containing the chlorophyll inside the screw-cap test tube to dry the solution. This chlorophyll a was confirmed by TLC(Thin layer chromatography) analysis. Then filter the solution with a filter paper poured into a $25-\mathrm{mL}$ conical flask. Then $0.5 \mathrm{M} \%$ of Chlorophyll-a added with $1 \% \mathrm{M}$ of stirred KDP solution this mixture was stirred more than 5 hours using a magnetic stirrer. The prepared solution was directly poured on the Petri disk and suitably closed and the solvent was allowed to evaporate at ambient temperature. After five days the nucleation took place and finally grown crystals have been obtained in the time of 15-20 days. Thus Synthesis material was purified by repeating the recrystallization process. Good transparent crystals were obtained due to spontaneous nucleation. Finally, good quality crystals were harvested and its structure is shown in fig.2 CHLAKDP single crystals, was synthesized by the following reaction.

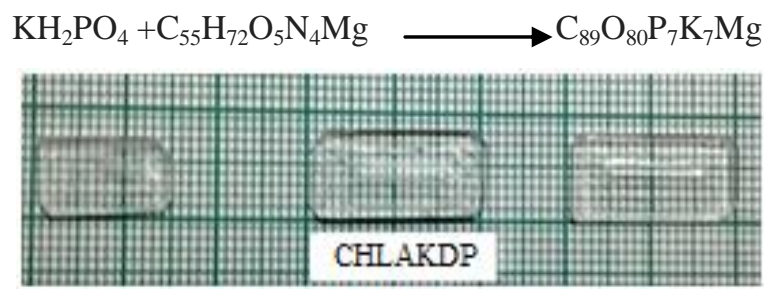

Fig.2 CHLAKDP grown crystal 


\section{RESUlTS AND DISCUSSION}

\subsection{FT-IR SPECTRA ANALYSIS}

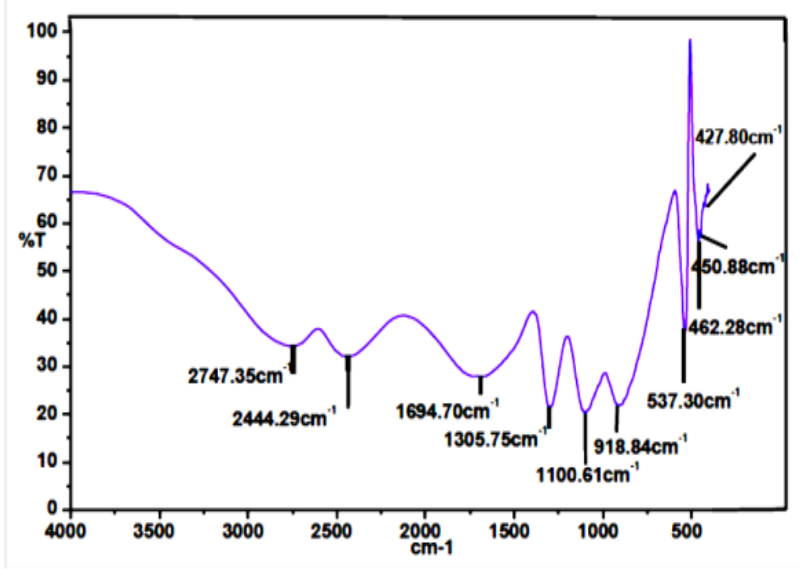

Fig 3 . FT-IR spectrum of CHLAKDP crystal

The FTIR study revealed to identify the shift in frequency of functional groups in KDP as a result of doping material. The FTIR analysis of the single crystals of Ficus religiosa chlorophyll-a doped potassium dihydrogen orthophosphate CHLAKDP was analyzed by employing a $66 \mathrm{~V}$ model spectrophotometer by a $\mathrm{KBr}$ pellet method in the wavenumber range $4000-400 \mathrm{~cm}^{-1}$. The FTIR spectrum analysis of the doped crystal (Fig.3) is compared to pure KDP crystal, which is already reported by various authors and analyzed $[12,13$,$] . The inclusion of peepal leaf chlorophyll-a in to KDP$ has been strongly verified. The bending vibrations due to $\left(\mathrm{H}_{2} \mathrm{PO} 4\right)$ in both doped and pure KDP are observed in the region $400-600 \mathrm{~cm}^{-1}$, At $\mathrm{P}=\mathrm{O}$ symmetric bending vibration shows a strong band at $538.54 \mathrm{~cm}^{-1}$ in pure KDP while it is slightly shifted to $537 \mathrm{~cm}^{-1}$ in the doped crystal. The absorption band at $918 \mathrm{~cm}^{-}{ }^{1}$ is fit for P-O-H bending vibration in the grown crystal while it is present at $897 \mathrm{~cm}^{-}{ }^{1}$ in pure KDP, at a frequency of $1305 \mathrm{~cm}^{-1}$ and $1367 \mathrm{~cm}^{-}{ }^{1} \mathrm{P}=\mathrm{O}$ stretching. Vibration occurs in Ficus religiosa leaves chlorophyll-a and pure KDP respectively, At frequency $1100 \mathrm{~cm}^{-1}$ in the doped crystal corresponds to C-H in plane bending vibration. The absorption peaks at $2747 \mathrm{~cm}^{-}{ }^{1}$ and $2444 \mathrm{~cm}^{-}{ }^{-}$corresponding to P-O-H asymmetric stretching and $\mathrm{O}=\mathrm{P}-\mathrm{OH}$ is stretching vibrations.

Table 1: Vibrational Band Assignments of CHLAKDP Crystals

\begin{tabular}{|l|c|l|}
\hline Pure KDP & $\begin{array}{l}\text { Chlorophyll-a } \\
\text { Doped KDP }\end{array}$ & $\begin{array}{l}\text { Functional Groups } \\
\text { Assignment }\end{array}$ \\
\hline 3467.76 & - & O-H Stretching \\
\hline 3450.21 & - & N-H Stretching \\
\hline 3029.6 & - & O-H Stretching \\
\hline 2971.61 & 2747.35 & $\begin{array}{l}\text { P-O-H } \\
\text { Asymmetric } \\
\text { Stretching }\end{array}$ \\
\hline 2126.46 & & O=P-OH \\
\hline
\end{tabular}

\begin{tabular}{|l|c|l|}
\hline & & Stretching \\
\hline 1739.63 & - & $\begin{array}{l}\text { O=P-OH } \\
\text { Stretching }\end{array}$ \\
\hline 1436.44 & & $\begin{array}{l}\text { O-P-O } \\
\text { Asymmetric } \\
\text { Stretching }\end{array}$ \\
\hline- & 1694.70 & C=C Stretching \\
\hline 1367.60 & 1305.75 & $\begin{array}{l}\text { O-P-O } \\
\text { Asymmetric } \\
\text { Stretching }\end{array}$ \\
\hline 1216.93 & & P=O Stretching \\
\hline 1229.24 & - & P=O Stretching \\
\hline 1093.07 & 1100.61 & P-O Stretching \\
\hline 897.81 & 918.84 & P-O-H Stretching \\
\hline 668.17 & - & P-O-H Stretching \\
\hline 539.56 & 537.30 & $\begin{array}{l}\text { HO-P-OH } \\
\text { Bending }\end{array}$ \\
\hline 527.9 & 462.38 & O-P-O Bending \\
\hline- & $427.80,450.8$ & C-C Deformation \\
\hline
\end{tabular}

\subsection{UV-Vis-NIR spectral analysis}

Optical absorption spectrum reveals inevitable information about the structure of the molecules because the absorption in the UV and visible light involves promotion of electrons in an orbit from the ground state to a higher energy state. The UV absorption has been recorded in the wavelength range from $190 \mathrm{~nm}$ to $1100 \mathrm{~nm}$ as shown in Fig. (3) It exhibits the highest transparency in the entire visible region and lowest cutoff wavelength $(336.9 \mathrm{~nm})$ substantive for effective laser frequency conversion [14]. The optical energy band gap of the material is to pivot roll to illustrate the electron transitions in different electronic band structures. The absorption coefficient was also calculated by using the transmittance spectrum, $\alpha=2.303[\log (1 / \mathrm{T})] / \mathrm{t}$, where $\mathrm{T}$ is the transmittance, $\alpha$ is the absorption coefficient, and $t$ is the thickness of the crystal. The band gap energies were calculated using the formula $\mathrm{Eg}=\mathrm{hc} / \lambda$, where $\mathrm{h}$ is the Planck's constant and $\mathrm{c}$ is the velocity of light. The values of the band gap of the grown crystals were determined from Tauc's extrapolation plot as depicted in Fig. 5. The graph plot between $(\alpha h v)^{2}$ and $h v$. It was seen that the band gap energy was $4.7 \mathrm{eV}$ for pure KDP it was already reported by various authors and $4.01 \mathrm{eV}$ for doped KDP[15]. The decreased band gap energy of $4.01 \mathrm{eV}$ in doped KDP can be attributed to the presence of Ficus religiosa leaves chlorophyll-a. Coefficient $\mathrm{K}$ increases with a wavelength $(\lambda)$ as shown in Fig.6. The refractive index value decreases with wavelength shows the normal dispersion behavior of the material. Reflectance and optical conductivity with wavelength compared with pure KDP was already reported by various authors is shown in Fig.7,[16].The propagation of electromagnetic waves through material evaluated using the relation $\mathrm{K}=\alpha \lambda / 4 \pi$. 


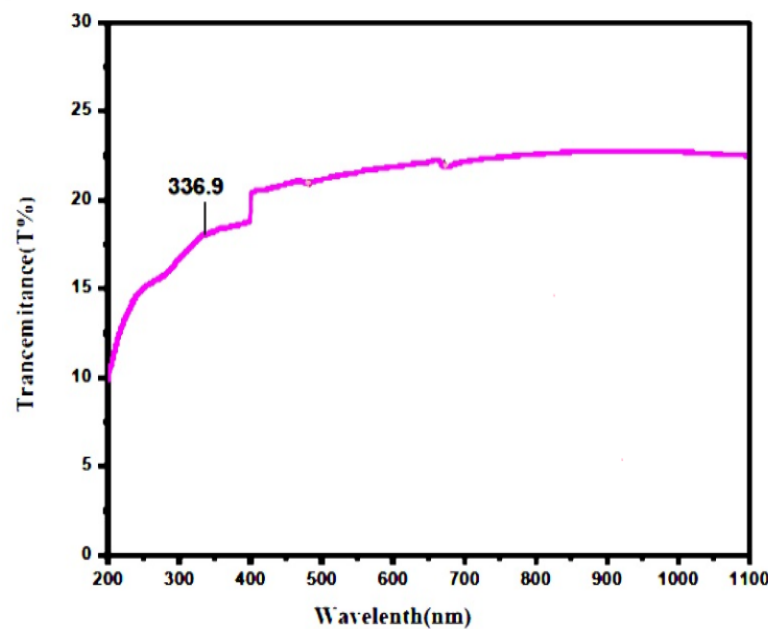

Fig 4 (a). Transmittance vs wavelength of CHLAKDP crystal

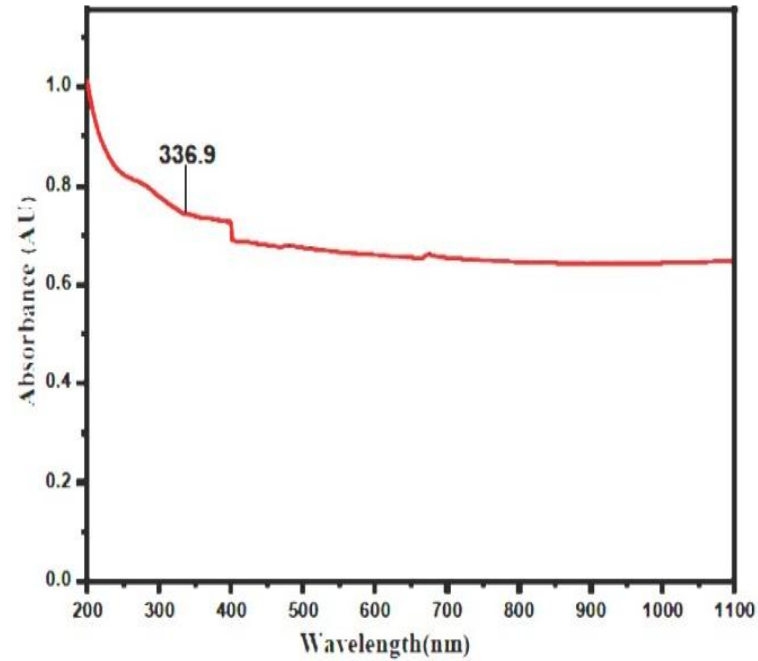

Fig 4 (b). Absorbance vs wavelength of CHLAKDP crystal

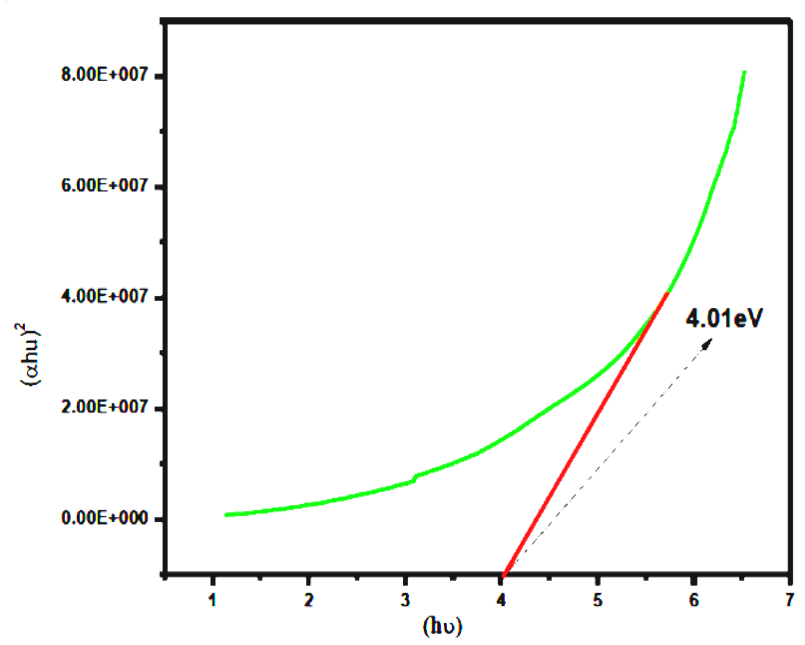

Fig 5. Tauc plot of CHLAKDP crystal

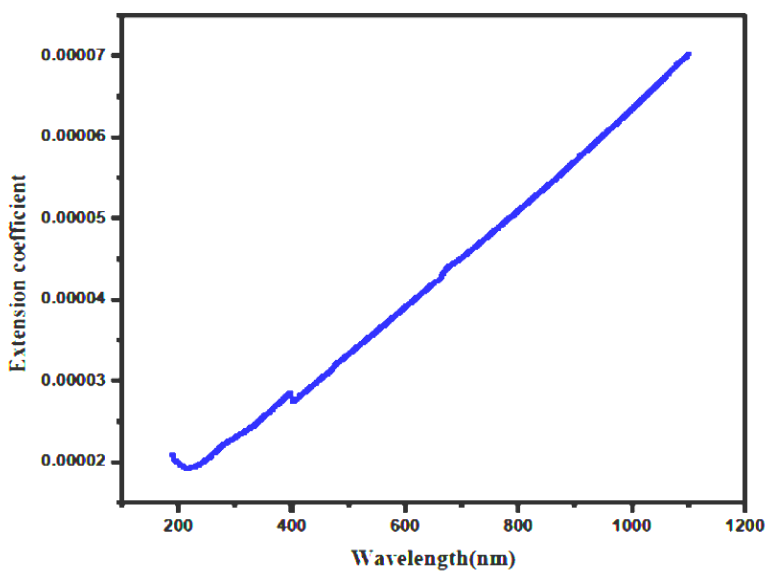

Fig 6. Extinction coefficient as a function of energy for CHLAKDP crystal

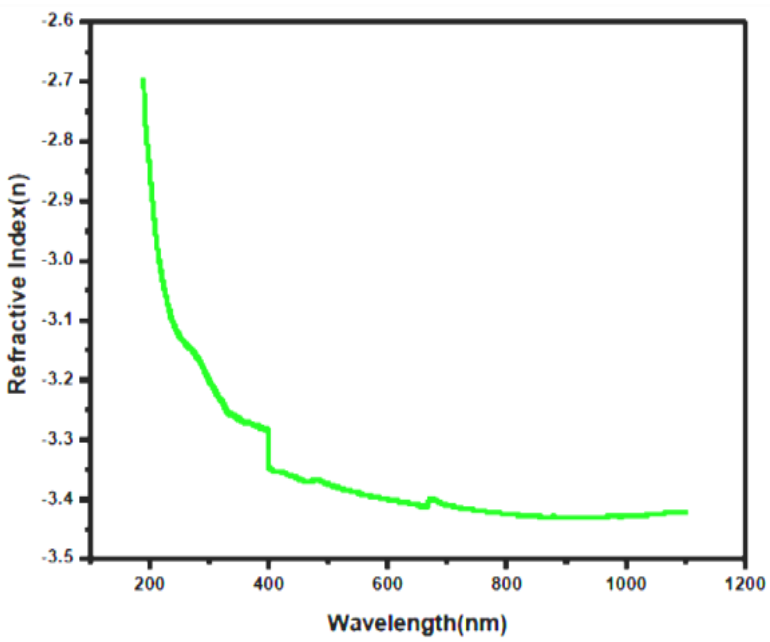

Fig 7. Refractive index as a function of wavelength for CHLAKDP crystal

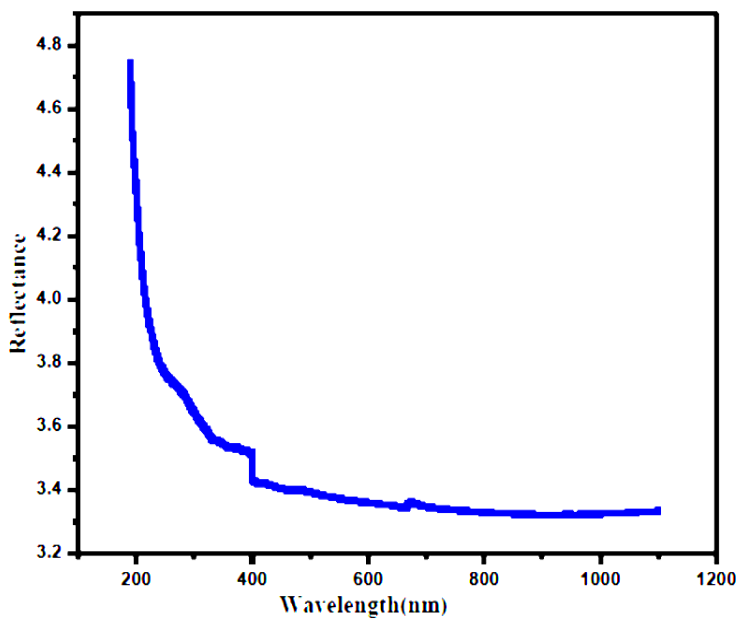

Fig 8. Reflectance as a function of wavelength for Peepal leaves chlorophyll-a doped KDP crystal 
Table 2. Parameters of pure and CHLKDP grown crystal

\begin{tabular}{|c|c|c|}
\hline Parameters & Pure KDP & $\mathrm{CHLA}+\mathrm{KDP}$ \\
\hline Cutoff wavelength $(\lambda)$ & $337 \mathrm{~nm}$ & $336 \mathrm{~nm}$ \\
\hline Band Gap (Eg) (eV) & $4.7 \mathrm{eV}$ & $4.01 \mathrm{ev}$ \\
\hline Reflectance (R) & 36.6 & 33.3 \\
\hline Extinction coefficient $(\mathrm{k})$ & $1 \mathrm{X} 10^{-4}$ & $1.91 \times 10^{-5}$ \\
\hline Refractive index(n) & 1.911 & 3.4 \\
\hline Opticalconductivity $\left(\sigma_{o p}\right)$ & 0.66 & 3.2 \\
\hline
\end{tabular}

\subsection{EDAX Analysis}

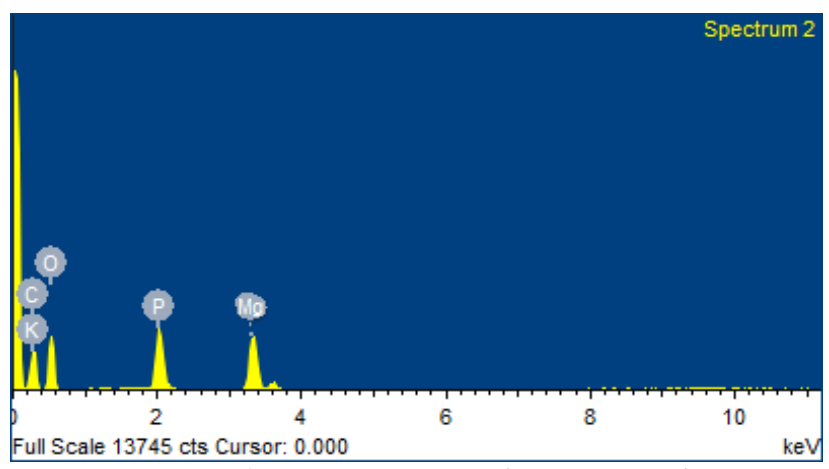

Fig 9. EDAX spectrum of grown crystal

EDAX stands for energy dispersive analysis by an $\mathrm{X}$-ray micro analyzer and it is a technique used for identifying the element composition of the specimen. In this work, the grown crystal was subjected to EDAX analysis using the OXFORD INSTRUMENT Energy dispersive micro analyzer. The EDAX spectrum of the Ficus religiosa leaves chlorophyll-a doped potassium dihydrogen orthophosphate crystal is shown in Fig (2). It confirms that doping elements are present in grown crystals. The weight percentage of the $\mathrm{C}$, $\mathrm{O}, \mathrm{P}, \mathrm{K}$ and $\mathrm{Mg}$ has been calculated and are shown in the Table (2).

Table 3. Element composition of grown CHLAKDP crystal

\begin{tabular}{|c|c|c|}
\hline Element & Weight\% & Atomic\% \\
\hline $\mathrm{C}$ & 37.20 & 48.30 \\
\hline $\mathrm{O}$ & 44.81 & 43.68 \\
\hline $\mathrm{P}$ & 8.06 & 4.06 \\
\hline $\mathrm{K}$ & 9.08 & 3.35 \\
\hline $\mathrm{Mg}$ & 0.85 & 0.61 \\
\hline
\end{tabular}

\subsection{Vickers Microhardness}

The Vicker's test is often easier to use than other hardness test. Hardness is the resistance offered by a material to the localized deformations created by indentations or scratching [17]. Since the required calculations are independent of the size of the indenter and the indenter can be used for all material irrespective of hardness number. The diamond indenter was pressed the plane of Ficus religiosa chlorophyll- a doped KDP crystal. The Vicker's hardness number was calculated using the relation.

$$
\mathrm{H}_{\mathrm{v}}=1.8544\left(\mathrm{P} / \mathrm{d}^{2}\right) \mathrm{kg} / \mathrm{mm}^{2}
$$

Where $\mathrm{P}$ is the applied load in $\mathrm{kg}$ and $\mathrm{d}$ is the diagonal length of the indentation impression in millimeter $(\mathrm{mm})$. A plot had drawn between Load Vs Hardness number of peepal leave chlorophyll a doped KDP crystal is shown in Fig (3). The micro hardness value gradually increases in the range of load from $25 \mathrm{~g}$ to $100 \mathrm{~g}$. This result shows the doping is perfectly located in the KDP crystal lattice and increases the mechanical property. From the literature it was found that the organic additives improved the mechanical strength of KDP crystals [18,19]. Fig (10) shown Micro hardness vs. Load graph for people leaves chlorophyll-a doped KDP crystal.

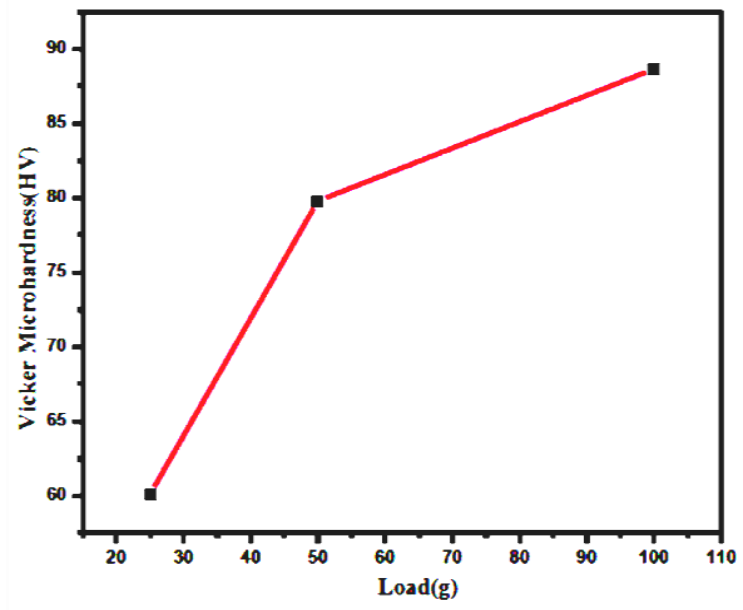

Fig 10. Microhardness vs Load graph for CHLAKDP crystal.

\subsection{Single crystal $X$-ray diffraction}

The cell parameters have been determined by single crystal XRD analysis for Ficus religiosa chlorophyll- a doped KDP grown crystals using Bruker Kappa APEX II single crystal X-ray diffractometer. The calculated lattice parameter values are $a=7.51 \AA, b=7.51 \AA$, and $c=7.01 \AA$ with angles $\alpha=\beta=\gamma=90^{\circ}$. The grown Peepal leaves chlorophyll a doped KDP crystal be allied to the tetragonal system with the I42d space group The grown Ficus religiosa chlorophyll a doped KDP crystal has been compared with the pure KDP crystal, it was already reported by various authors. The Lattice parameter values of chlorophyll a doped KDP grown crystals are scheduled in Table (4), from the table it is clear that the doping has brought about a change in the cell dimensions and cell volume. It has been confirmed that the doping material included on KDP crystal lattices. 
Table 4. Unit cell parameters of CHLAKDP crystal.

\begin{tabular}{|c|l|l|l|c|c|c|}
\hline Crystal & $\begin{array}{l}\mathrm{a} \\
(\AA)\end{array}$ & $\begin{array}{l}\mathrm{b} \\
(\AA)\end{array}$ & $\begin{array}{l}\mathrm{c} \\
(\AA)\end{array}$ & $\begin{array}{l}\text { Volume } \\
\left(\mathrm{A}^{3}\right)\end{array}$ & $\alpha=\beta=\gamma$ & System \\
\hline $\begin{array}{c}\text { Pure } \\
\text { KDP }\end{array}$ & 7.44 & 7.44 & 6.94 & 384 & $90^{\circ}$ & $\begin{array}{c}\text { Tetrag } \\
\text { onal }\end{array}$ \\
\hline $\begin{array}{c}\text { Doped } \\
\text { KDP } \\
\text { crystals }\end{array}$ & 7.51 & 7.51 & 7.01 & 396 & $90^{\circ}$ & $\begin{array}{c}\text { Tetrag } \\
\text { onal }\end{array}$ \\
\hline
\end{tabular}

\subsection{Photoluminescence}

The PL emission spectra were recorded on the solid samples of as grown Ficus religiosa chlorophyll- a doped KDP crystal. PL emission spectra for a grown sample were recorded in the wavelength range $240-800 \mathrm{~nm}$ with an excitation wavelength of $446 \mathrm{~nm}$ and $669 \mathrm{~nm}$ was demonstrated. The PL spectra for CHLAKDP crystal are shown in Figure(11).The broad band was observed in the emission spectrum of CHLAKDP crystals between $400 \mathrm{~nm}$ $700 \mathrm{~nm}$. This emission spectrum is attributed to transition from the conduction band to valence band and shows blue and reds shifts. It may be expected in molecules that will be aromatic or contain multiple conjugated double bonds with a high degree of resonance stability.

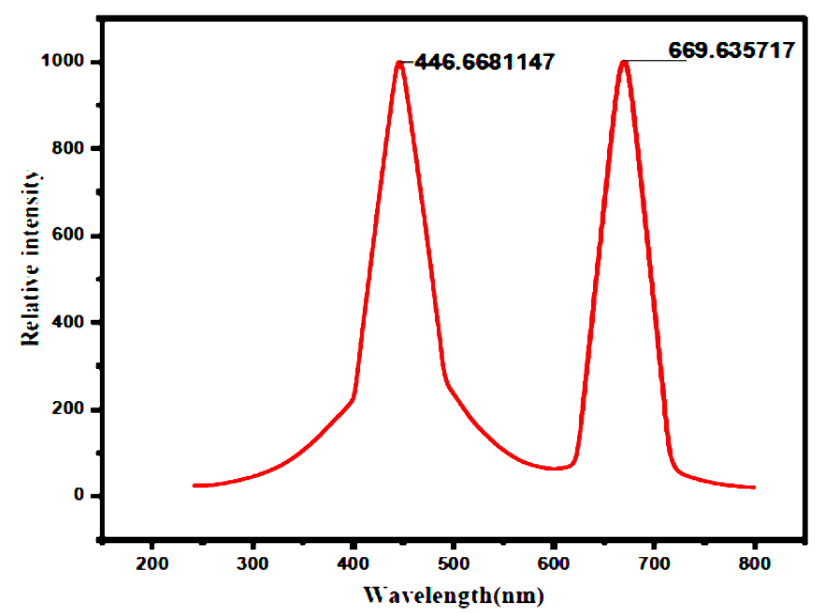

Fig 11. Photoluminescence spectra of CHLAKDP crystal.

\section{CONCLUSION AND FUTURE SCOPE}

Bulk single crystal of CHLAKDP has grown by slow evaporation techniques. FTIR analysis confirmed the inclusion of the dopant into KDP and identified the shift in frequency band due to doping. From the optical transmission analysis the band gap of grown crystal was found to be 4.1 $\mathrm{eV}$, and the band gap value indicates that the grown crystal possesses dielectric behavior to promote polarization when powerful radiation is incident on the material. The optical parameters such as reflection, absorption, reflectance, coefficient, electrical conductivity, optical conductivity and refractive index were calculated. From these studies, this crystal is applicable for optoelectronic applications . EDAX analysis confirmed the chemical composition of grown crystals. Vickers micro hardness has been found that the grown crystal belongs to soft material with the Bio-organic additive added system. Single crystal $\mathrm{X}$ - ray diffraction analysis revealed that the title crystals are affiliated to the tetragonal system with space group I42d.The title material has blue and red color fluorescence emission at 446 and 669 $\mathrm{nm}$.

\section{ACKNOWLEDGEMENTS}

The authors thank SAIF, IIT Madras, Chennai for providing single crystal XRD. The authors acknowledge the St. Joseph College, Trichy, India, for spectral facilities.

\section{REFERENCES}

[1] A.Yokotani, T. Sasaki, K. Yoshida, T. Yamanaka, C. Yamanaka, "Improvement of the bulk laser damage threshold of potassium dihydrogen phosphate crystals by ultraviolet irradiation", Applied Physics Letters. Vol.48, Issue.16, PP. 10301032,1986

[2] N. Zaitseva, L. Carman, "Rapid growth of KDP-type crystals", Progress in Crystal Growth, Characterization of Materials, Vol.43, Issue.1, PP. 1-118, 2001

[3] N.P. Zaitseva, J.J. De Yoreo, M.R. Dehaven, R.L. Vital, K.E. Montgomery, M. Richardson, L.J. Atherton, "Rapid growth of largescale (40-55 cm) KH2PO4crystals", Journal of Crystal Growth, Vol.180, Issue.2, PP.255-262,1997.

[4] I. Pritula, A. Kosinova, M. Kolybayeva, V. Puzikov, S. Bondarenko, V. Tkachenko, V. Tsurikov, O. Fesenko, "Optical, structural and microhardnessproperties of KDP crystals grown from urea-doped solutions", Material Research Bulletin, Vol.43, PP. 2778-2789, 2008.

[5] A.E. Voloshin, S.S. Baskakova, E.B. Rudneva, " Study of the defect formation in KDP crystals grown under extremely high supersaturation”, Journal of Crystal Growth, Vol.457 ,PP.337342, 2017.

[6] L.J.Chen Jianzhong, LinSukun, YangFengtu,WangJiahe, "Effect Of alcoholic additives on the nucleation of KDP and DKDP crystals", Journal of Crystal Growth, Vol.179, Issue .1-2, PP. 226230,1997.

[7] Guohui Li, Xue Liping, Genbo Su, Xinxin Zhuang, Zhengdong Li, Youping He, "Study on the growth and characterization of KDP-type crystals",Journal of Crystal Growth, Vol.274, PP. 555-562,2005.

[8] Lieut. Col. Warner F. Bowers Medical Corps, Army Of The United States"Chlorophyll In Wound Healing And Suppurative Disease”. Vol.73, Issue 1, PP.37-50, 1947

[9] Mario G. Ferruzzia, Joshua Blakesleeb "Digestion, absorption, and cancer preventative activity of dietary chlorophyll derivatives" Nutrition Research ,Vol.27, Issue.1,.PP.1 - 12, 2007.

[10] Durga DM and Banu N: "Study of Antioxidant Activity of Chlorophyll From Some Medicinal Plants, Paripex"-Indian Journal of Research Vol.2 , Issue.4, PP. 2250-1991, 2015.

[11] Anittha1 , L. Mullainathan. "Chlorophyll and Morphological Mutations Induced by Chemical Mutagens EMS, DES in (Setaria italica(L.)Beauv.)Var.CO(Te)7 in M2 Generation”. International 
Journal of Scientific Research in biological sciences, Vol.5, Issue.6, PP.61-65, 2018.

[12] R.R.Saravanan, S.Seshadri, M.Murugan and V.Manivannan, "Structural,Optical properties and effect of amino acid on growth of KDP crystals "Indian Journal of Pure and Applied Physics, Vol.51, Issue.4, PP.254-259, 2013.

[13] R.Kayalvizhi and G.Meenakshi, "Growth and Characterization of Pure and Neem Leaves Extract Doped Potassium Dihydrogen Phosphate(KDP) Crystal" International Journal of Innovative Technology and Exploring Engineering, Vol.3,Issue 2,PP.22783075, 2013.

[14] T.C. Sabari Girisun, S. Dhanuskodi, "Linear and nonlinear optical properties of tris thiourea zinc sulphate single crystal" Crystal Research and Technology.Vol.44, Issue.12, PP.1297-1302, 2009.

[15] Mohd Anis , M.D.Shirsat , GajananMuley , S.S.Hussaini, “ Influence of formic acid on electrical, linear and nonlinear optical properties of potassium dihydrogen phosphate(KDP) crystals" journal of Physica B,condensed matter Vol.449,PP.61-66,2014.

[16] S. Nirmala Sri Devi, E.K. Girija , "A comparative study on the effect of l-tartaric acid and sodium bicarbonate on the growth and characterization of KDP single crystals". Optik Vol.164 PP.498$509,2018$.

[17] S. Sasi, R. Robert, S. Arumugam, C. Inmozhi " Growth, optical and spectroscopic studies of $l$ - crystalline doped KDPsingle crystals" Optik (2015).

[18] N.P.Rajesh,V.Kannan, P.S.Raghavan, P.Ramasamy, C.W. LAN, "Optical and Microhardness studies of KDP crystals grown from aqueous solutions with organic additives", Material Letters Vol.52 Issue.4-5,PP.326-328, 2002.

[19] Z. Delci, D. Shyamala, S. Karuna, A. Senthil, and A.Thayumanavan of "Optical, Thermal and Hardness in KDP crystals by Boron Doping" International Journal of ChemTech Research Vol.4, No.2, PP.816-826,2012.

\section{AUTHORS PROFILE}

Mr. S. Senthilkumar pursued Bachelor of Science in Rajah Serfoji Government College, Thanjavur, Master of science in Adaikalamatha college, Vallam, Thanjavur, Tamil Nadu, India in 2004, 2009, and M.Phil., in A.V.V.M. Sri Pushpam College, Poondi, Thanjavur, Tamil Nadu, India in 2010. He is currently pursuing Ph.D as a part - time research scholar in the A.V.V.M. Sri

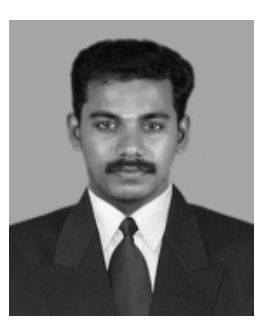

Pushpam College (Autonomous), Poondi, Thanjavur (affiliated to Bharathidasan University) Tamil Nadu, India. Currently working as Assistant professor in Physics, Parisutham institute of technology and science, Thanjavur, Tamil Nadu, India. His main research work focuses on Material science. He has 10 years of teaching and research experience at UG and PG level.

Dr. C. Ramachandraraja pursued M.Phil., and Ph.D from Annauniversity Chennai, India. Presently working as professor of Physics, Government Arts college Kumbakonam, Tamil Nadu, India. Having 30 years of teaching and research experience at UG, PG, M.Phil., and Ph.D, level. Published more than 92 research papers in reputed, peer reviewed, citation indexed international journals (Elsevier, Springer, Science direct) and international level conference.
Dr. R. Manimekalai pursued M.Sc., M.Phil., and Ph.D from Bharathidasan University, Tiruchirappalli in 1988, 1989 and 2014. Presently working as Associate professor of Physics, A.V.V.M. Sri Pushpam College, Poondi, Thanjavur-613 503, Tamil Nadu, India. Having 29 years of teaching and research experience at $\mathrm{UG}, \mathrm{PG}$ and M.Phil., level. Acting as research advisor in physics from the year 2016 onwards in

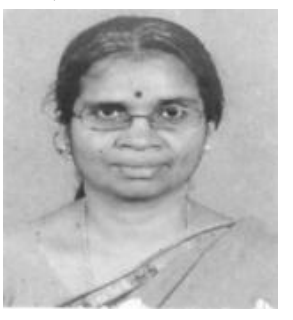
A.V.V.M. Sri Pushpam College (Autonomous), Poondi, Thanjavur (affiliated to Bharathidasan University). Published more than 12 research papers in reputed, peer reviewed, citation indexed international journals (Elsevier, Springer, Science direct) and international level conference. At present guiding eight Ph.D and six M.Phil., research Scholars. 